current safe alternatives are available, stricter validation should be required before marketing of alternative formulations, particularly when premarketing studies imply a substantial risk. Thirdly, postmarketing surveillance should be intense, given the limited premarketing testing of new vaccines. This could take the form of a mandatory register of all recipients until a sufficient number of vaccinated people has accrued to identify potentially serious adverse effects. Low reporting rates make spontaneous reporting inadequate. Manufacturers need to be asked to undertake more controlled monitoring as part of the grant of marketing authorisations. Access to case notes also needs to be improved. In the Swiss study the investigators were able to enrol only about a third of the identified cases. ${ }^{7}$ The crisis surrounding the vaccine for measles, mumps, and rubella (MMR) shows that consumers are intensely averse to risk, and the challenge for regulators and manufacturers is to restore confidence in vaccination. Both false alarms and postmarketing withdrawals of the vaccine make this more difficult. Fourthly, more research is required on the mechanisms by which poorly understood adverse effects of non-parenteral vaccines, such as Bell's palsy and intussusception, develop. This will require funding, probably by charities and government agencies.

Given increasing microbial resistance to antibiotics, research on vaccines needs to be increased. The once intense debate initiated over four decades ago about the relative merits of the oral and parenteral polio vaccines continues. ${ }^{4}$ A decade ago, Howson and Fineberg discussed the ricochet of magic bullets in their commentary on the adverse effects of pertussis and rubella vaccines. ${ }^{10}$ We have yet to achieve Paul Erhlich's dream of the magic bullet. ${ }^{11}$ We have an intense dislike of friendly fire, particularly resulting from pre-emptive action about dangers that we cannot perceive clearly. Tradeoffs between risks and benefits will always be necessary. ${ }^{12}$ Ironically, with concerns about bioterrorism, research into smallpox vaccination is restarting. Any collateral benefits from such research are to be welcome.

\section{Alain Li Wan Po Director, Professor of Clinical} Pharmaceutics

Centre for Evidence-Based Pharmacotherapy, Medicines Research Unit, Aston University, Birmingham B4 7ET

(a.liwanpo@aston.ac.uk)

Competing interests: AP served as a member of the UK Committee on Safety of Medicines.

1 Stratton KR, Durch JS, Lawrence RS. Vaccines in the 21st century. A tool for decision making. Washington: National Academy Press, 2000.

Non-parenteral vaccines [theme issue]. Adv Drug Delivery Rev 1995;18:1114.

Esteves K. Safety of oral poliomyelitis vaccine: results of a WHO enquiry. Bull WHO 1988;66:739-46.

4 Vastag B. At polio's end game, strategies differ. JAMA 2001:286:2797-9.

5 Holmgren J, Lycke N, Czerkinsky C. Cholera toxin and cholera B subunit as oral-mucosal adjuvant and antigen vector system. Vaccine as oral-mucosal

6 Clemens JD, Hartzog NM, Lyon FL. Adjuvant activity of Escherichia coli heat-labile enterotoxin and effect on the induction of oral tolerance in mice to unrelated protein antigens. Vaccine 1988;6:268-77.

7 Mutsch M, Zhou W, Rhodes P, Bopp M, Chen RT, Linder T, et al. Use of the inactivated intranasal influenza vaccine and the risk of Bell's palsy in Switzerland. N Engl J Med 2004;350:896-903.

8 Murphy TV, Gargiullo PM, Masoudi MS, Nelson DB, Jumaan AO, Okoro MS, et al. Intussusception among infants given an oral rotavirus vaccine. NEngl J Med 2001;344:564-72.

9 Lang D Safety evaluation of toxin adjuvants delivered intranasally. Lang D. Safery evald 10 Howson CP, Fineberg HV. The ricochet of magic bullets: summary of the Institute of Medicine report. Adverse effects of pertussis and rubella vaccines. Pediatrics 1992;89:318-24

11 MMR. The facts, the claims, the realities and the questions that remain unanswered. Independent 2004, February 24: p1, 4 and 5.

12 Fujihashi KKT, van Ginkel FW, Hagiwara Y, McGhee JR. A dilemma for mucosal vaccination: efficacy versus toxicity using enterotoxin-based adjuvants. Vaccine 2002;20:2431-8.

\title{
Transplantation for alcoholic liver disease
}

\section{Transplants are appropriate for selected people with alcohol induced liver damage}

$\mathrm{L}$ iver transplantation for patients with alcoholic liver disease raises issues and controversies not seen with other indications. This is partly based on the perception that alcoholic liver disease is self induced, despite the fact that clear genetic and environmental influences exist, but also because the recipient may return to a pattern of drinking that will damage the graft. Although such medical issues should be discussed openly, uninformed debate risks undermining public confidence in the use of the donated livers and may result in fewer organ donations.

Though many recipients return to some degree of alcohol consumption after transplantation overall this is to a degree similar to that in patients grafted for other conditions. Fewer than $10 \%$ return to drinking more than 21 units per week. ${ }^{2}$ At five years, less than $5 \%$ of grafts are lost as a direct or indirect consequence of alcohol misuse. ${ }^{3}$ This contrasts with graft loss of $10 \%$
Most, if not all, transplant candidates have already stopped drinking, and appropriate screening will detect all but the most determined of alcoholics. The length of abstinence before transplantation does not reliably predict abstinence afterwards, so no justification exists for a fixed arbitrary period of abstinence before the transplantation ${ }^{5}$; death may be the price of proving abstinence. However, a period of abstinence may identify patients in whom recovery of liver function may occur and so obviate the need for transplantation. It may also allow time to explore why the person has drunk to a damaging extent and to put in place coping strategies and develop support networks to prevent a return to previous patterns of misuse. Serious concerns remain about the place of transplantation for people with alcoholic hepatitis, a situation in which time is short and a full assessment often not possible, or people in whom failure to change drinking behaviour or engage with 
addiction services has been long standing and consistent.

So what about the patient with alcoholic liver disease who has received a transplant and returns to alcohol consumption? From an addiction perspective, a patient who has fulfilled the criteria for a diagnosis of alcohol dependence is at risk of returning to previous levels of consumption when alcohol is taken, although whether this pattern is altered after a transplant is uncertain as transplantation itself may have a rehabilitative effect. ${ }^{6}$ Most patients who have received transplants for alcoholic liver disease are unlikely to have met the criteria for a diagnosis of dependence, and resumption of drinking may therefore be less risky.

This leaves a dilemma regarding considerations from an addiction perspective for such transplant candidates. Some patients can return to some alcohol use after transplantation with no appreciable risk to the graft. People with a history of alcohol dependence, however, are unlikely to be able to resume moderate drinking without a risk of reverting to previous heavy levels of consumption. By insisting on lifelong abstinence for all, are we attempting to avoid all risk to the graft without considering quality of life and individual strengths and values? We should aim for harm minimisation and moderation for the majority and accept a risk to the graft for a small minority.

We do not have consensus on what constitutes a relapse or recidivism, and what degree of alcohol consumption, if any, is acceptable. After transplantation about $8-22 \%$ of patients relapse (consumption of any amount of alcohol) within six months and 10-30\% relapse overall, ${ }^{7}$ whereas with conventional treatment for alcohol dependence a $60-80 \%$ relapse rate at two years is common. Even in an era of donor shortage, the question should therefore not be whether patients with alcoholic liver disease should receive transplants but whether enough is being done to support such patients through a successful operation.

Concerns about the effects of relapse leading to recurrent graft damage and non-compliance are applied to patients who have received grafts for alcoholic liver disease but not other indications. For example, obesity may in itself result in end stage liver disease requiring liver transplantation, will accelerate the progression of hepatitis $\mathrm{C}$ virus disease, and may result in graft damage. ${ }^{8}$ Should patients in whom obes- ity has had a role in the development of end stage liver disease be offered transplantation only if they lose weight before the procedure and agree to avoid over eating afterwards? Non-compliance with medication as a consequence of a return to drinking occurs in only a small proportion of drinkers who relapse. ${ }^{9}$ In people with transplants, the greatest risk of non-compliance is not among those grafted for alcoholic liver disease but among teenagers. ${ }^{10}$ Yet few argue that adolescents should not receive transplants because they might damage or lose their graft from non-compliance and in this event be denied a second graft.

Debate fuelled by uninformed comments will serve potential donors, their families, and recipients poorly. Those involved in transplantation need to show that donated livers are used wisely, ethically, and fairly and so should reassure the public to understand that selected people with alcohol induced liver damage are appropriate candidates for transplantation and that a rational basis is used to assess and treat such potential patients.

Kerry Webb clinical nurse specialist, alcohol liaison

James Neuberger consultant physician

(james.neuberger@uhb.nhs.uk)

Liver Unit, Queen Elizabeth Hospital, Birmingham B48 7ST

Competing interests: JN has received educational support from pharmaceutical companies, including Roche, Novartis, and Fusjisawa.

1 Mackie J, Groves K, Hoyle A, Garcia C, Garcia R, Gunson B, Neuberger J Orthotopic liver transplantation for alcoholic liver disease: a retrospective analysis of survival, recidivism and risk factors predisposing to recidivism. Liver Transpl 2001;7:418-27.

2 Pageaux GP, Bismuth M, Perney P, Costes V, Jaber S, Possoz P, et al. Alcohol relapse after liver transplantation for alcoholic liver disease: does it matter? J Hepatol 2003;38:629-34.

3 Lucey MR, Carr K, Beresford TP, Fisher LR, Shoeck V, Brown KA, et al. Alcohol use after liver transplantation in alcoholics: a clinical cohort follow-up study. Hepatology 1997;25:1223-7.

4 Gane E. The natural history and outcome of liver transplantation in hepatitis C virus-infected recipients. Liver Transpl 2003;9(suppl 3):s28-34.

Neuberger J, Schulz K-H, Day C, Fleig W, Berlokovich GA, Berenguer M, Neuberger J, Schulz K-H, Day C, Fleig W, Berlokovich GA, Berenguer M,
et al. Transplantation for alcoholic liver disease. J Hepatol 2002;36:130-7. et al. Transplantation for alcoholic liver disease. J Hepatol 2002;36:130-7.
Vaillant GE. The natural history of alcoholism and its relationship to liver transplantation. Liver Transpl Surgery 1997;3:304-10.

7 Pageaux GP, Perney P, Larrey P. Liver transplantation for alcoholic liver disease. Addict Biol 2001;6:301-8.

8 Burke A, Lucey MR. Non-alcoholic fatty liver disease, non-alcoholic steatohepatitis and orthotopic liver transplantation. Am J Transpl 2004;4:68693.

9 Mackie J, Groves K, Hoyle A, Garcia C, Garcia R, Gunson B, et al. Orthotopic liver transplantation for alcoholic liver disease: a retrospective analysis of survival, recidivism and risk factors predisposing to recidivism. Liver Transpl 2001;7:418-27.

10 Chapman JR. Compliance: the patient, the doctor and the medication? 0 Chapman JR. Compliance: the
Transplantation 2004;77:782-6.

\section{Open access to industry's clinically relevant data}

\section{Urgently needed, but when will we get it, and in what form?}

$\mathrm{L}$ ast month GlaxoSmithKline announced that it would publish summaries of all its clinical trials of a new product once it had been launched. ${ }^{1}$ This decision followed news of a lawsuit brought by New York State alleging that the company had concealed the results of trials of paroxetine because they might have spoilt marketing plans. GSK said it had been considering the move for some months. A similar sounding policy was announced by Glaxo Wellcome in $1998^{2}$ but seems to have been quietly abandoned in 2000 after the merger with Smith KlineBeecham.

The arguments for free public access to all clinically relevant data on a company's drug have been stated 